\title{
EFFECTS OF STREPTOZOTOCIN-INDUCED DIABETES ON FEEDING STIMULATED BY CENTRALLY ADMINISTERED OPIOID AGONISTS
}

\author{
Blake A. Gosnell1, Martha Grace ${ }^{2}$, Charles J. Billington² \& Allen S. Levine 2
}

${ }^{1}$ Department of Psychiatry, University of Michigan, 8D8806/UH/Box 0116, Ann Arbor, MI, 48109-0116, and 2Neuroendocrine Research Laboratory, VA Medical Center, Minneapolis, MN, 55417.

(Received in final form April 21, 1989)

\section{Summary}

The potencies of several opioid agonists are reduced in diabetic animals and in animals made hyperglycemic via injections of glucose. In this report we examined the effects of streptozotocin-induced diabetes on the feeding responses to centrally administered opioid agonists with differing receptor selectivities. The selective mu receptor agonist Tyr-DAla-Gly-(Me)Phe-Gly-ol (DAGO) caused a larger increase in intake in diabetic rats than in controls. In both groups feeding responses were greater on the fourth day of daily injections than on the first day. The delta receptor agonist [D-Ser ${ }^{2}$, Leu ${ }^{5}$ ]-enkephalin-Thr6 (DSLET) stimulated intake in controls but not in diabetics. However, the elevated baseline and large variability in intake of the diabetics in this experiment prevent drawing a conclusion on diabetes-induced changes in the potency of this peptide. No differences between controls and diabetics were apparent in the feeding responses to $U 50,488 \mathrm{H}$, a selective kappa receptor agonist. These data suggest that diabetes may differentially affect the classes of opioid receptors or the binding of ligands to these receptors.

Opioid agonists and antagonists cause increases and decreases, respectively, in food and water intake, and endogenous opioid peptides are thought to contribute to the regulation of appetite (see I, 2 for reviews). Since some effects of opiates are altered by the glycemic state of the animal, we examined the effects of chemically induced diabetes on the feeding responses to central administration of selective opioid agonists.

Simon and Dewey (3) and Simon et al. (4) reported that opiate-induced analgesia was decreased in mice made diabetic by treatment with streptozotocin (STZ), as well as in mice given injections of hypertonic dextrose or fructose.

Conversely, hypoglycemic mice were more sensitive to the antinociceptive effects of morphine (3). Diabetic mice also developed less physical dependence to morphine 
than non-diabetic mice (5). Similarly, intraperitoneal injections of glucose blocked the increase in tail skin temperature observed during naloxone-precipitated morphine withdrawal (6).

In vitro, the inhibitory effect of normorphine on electrically-induced contractions of the guinea pig ileum and mouse vas deferens were reduced by the addition of glucose to the bathing medium (7). This finding suggests that the effect of diabetes on in vivo responses to opiates is due to elevated glucose levels rather than to some other changes associated with diabetes. This possibility is supported by the work of Brase et al. (8), which demonstrated that glucose decreases high affinity binding of naloxone in mouse brain membranes. However, these authors indicate that decreased binding affinity cannot completely explain the in vivo effects of hyperglycemia on opioid responses; they suggest that glucose metabolism, glucoseendogenous opioid interactions or an interaction of glucose with ion transport mechanisms may also be important.

Recently, we reported that repeated daily injections of morphine caused a greater weight loss in controls than in STZ-diabetic rats (9). Similarly, daily morphine injections reduced feed efficiency to a greater extent in controls than in diabetic rats. Thus, although it is unclear why morphine increases short-term intake (9-13) yet decreases total daily intake and rate of body weight gain when given in repeated daily injections $(9,11,14,15)$, the attenuated effects of long-term morphine treatment in diabetic rats are consistent with studies cited above.

The opiate antagonist naloxone has been shown to cause a decrease in food intake in a number of species, including man (see 1). In short term feeding trials, STZtreated diabetic rats appeared to be less sensitive to naloxone than controls (16). However, when the rats were tested in a novel environment, diabetic rats were more sensitive to naloxone than control animals. Similarly, genetically obese hyperglycemic mice and streptozotocin-induced diabetic mice were more sensitive to naloxone than lean controls when tested in a novel environment (17).

The aforementioned in vivo studies have relied on peripheral administration of agonists and antagonists. In the experiments described here, we injected selective opioid agonists into the lateral cerebral ventricle of normal rats and rats made diabetic by intravenous injection of STZ. The peptides Tyr-D-Ala-Gly-(Me)Phe-Gly-ol (DAGO) and $\left[D-\right.$ Ser $^{2}$, Leu $^{5}$ ]-enkephalin-Thr 6 (DSLET) were used as selective agonists of mu and delta opioid receptors, respectively $(18,19)$. Both peptides have been shown to stimulate food intake when injected intracerebroventricularly (icv) $(20,21)$. We also tested $\mathrm{U}-50,488 \mathrm{H}$, a selective kappa agonist (22), which has been found to increase intake when injected subcutaneously $(23,24)$ or icv (unpublished observations).

\section{Methods}

DAGO, DSLET and U50,488H were tested in three separate experiments. Male Sprague-Dawley rats were housed individually in stainless steel cages and given food and water ad libitum. Lights were on from 7 AM to 7 PM. In each experiment, approximately one half of the animals were made diabetic by the injection of $65 \mathrm{mg} / \mathrm{kg}$ of streptozotocin into the tail vein. To verify that STZ-treated rats were hyperglycemic, $0.1 \mathrm{ml}$ blood samples were taken from a tail vein 4-6 days later and blood glucose was determined by a glucose oxidase kit (Sigma Chemical Co., St. Louis, MO). All diabetic rats had blood glucose levels greater than $400 \mathrm{mg} / \mathrm{dl}(619 \pm 12 \mathrm{mg} / \mathrm{dl})$. Five to nine days after STZ treatments, a stainless steel guide cannula (20 gauge) was implanted into the lateral cerebral ventricle of each rat. Coordinates for the tip of the guide 
cannula were $1 \mathrm{~mm}$ posterior and $1.5 \mathrm{~mm}$ lateral to bregma and $3.5 \mathrm{~mm}$ ventral to the surface of the skull. At least 7 days were allowed for recovery from this procedure.

In the first experiment, STZ-treated and control rats were given intracerebroventricular (icv) injections of 0 (saline), 1, 3 or $10 \mathrm{nmol}$ of DAGO. Thus, there were a total of 8 groups ( 2 glycemic states $\times 4$ drug doses), with 4-5 rats per group. All injections were given in a $5 \mu$ l volume through a 25 gauge cannula which extended $1 \mathrm{~mm}$ beyond the tip of the guide cannula. Immediately after injections, rats were returned to their home cages and a pre-determined amount of laboratory chow was placed in the floor of each cage. Intake was determined by weight 2, 4 and 6 hours after injection and was corrected for spillage at each measurement. We have found these times and the range of doses tested to be adequate to characterize the feeding responses to a number of centrally or systemically administered opioid agonists $(12,20,21$ and unpublished observations). To assess the effects of repeated opioid administration, these procedures were repeated in an identical manner on the following three days, with each rat receiving the same dose on all four days.

Data were analyzed with a three-factor analysis of variance (ANOVA). A separate ANOVA was performed at each measurement (2, 4 and 6 hours). Drug dose and diabetic state were between-groups factors, and the trials on Days 1 and 4 were treated as a repeated-measures factor. Data from Days 2 and 3 were not included in this analysis. Within each day and diabetic state, mean intakes of the groups receiving DAGO were compared to the saline-injected group with Dunnett's test.

In the second experiment, DSLET was tested in naive rats with procedures and doses identical to those described above for DAGO $(n=6-11$ per group). In the third experiment, the kappa agonist $U 50,488 \mathrm{H}$ was tested in naive rats with procedures identical to those in the first two experiments with the exception that the doses used were 0 (saline), 21, 64 and $215 \mathrm{nmol}(\mathrm{n}=6-10$ per group).

DAGO and DSLET were purchased from Sigma Chemical Company (St. Louis, $\mathrm{MO}$ ) and $\mathrm{U} 50,488 \mathrm{H}$ was purchased from the Upjohn Company (Kalamazoo, MI).

\section{Results}

Feeding Trials: To simplify presentation of the results from the DAGO trials, only four hour cumulative intake data are represented graphically. For DSLET and $\mathrm{U} 50,488 \mathrm{H}$, only 2 hour intakes are shown. In our laboratories, we have found that the maximum effects of these agonists are generally observed in these time periods $(20,21$ and unpublished observations).

DAGQ: A three-factor ANOVA indicated significant main effects of DAGO at 2, 4 and 6 hours, of diabetes at 4 and 6 hours and of treatment day at 2 and 4 hours.

Furthermore, the interaction between DAGO and diabetes was significant at 6 hours and approached the

significance criterion of $p<.05$ at 4 hours $(p=.058)$. None of the interactions involving treatment day were significant. On Day 1 , none of the doses increased intake in controls at 2,4 or 6 hours. In diabetics, the 10 nmol dose significantly increased 4 and 6 hour intake. Intakes of the groups receiving 1 and 3 nmols were elevated but not significantly greater than the saline-injected group. Four hour intake data are represented in Figure 1.

Both diabetics and controls were more responsive to DAGO on Day 4 than on Day 1. All three doses increased 2 hour intake in controls, and 4 hour intake was 
increased by the 1 and $10 \mathrm{nmol}$ doses. Intake in the $3 \mathrm{nmol}$ group was elevated but was approximately $0.2 \mathrm{~g}$ less than that required for statistical significance. In diabetics, the $10 \mathrm{nmol}$ dose increased 2 hour intake, and all three doses increased 4 and 6 hour intake. Although a similar dose range was effective in both groups, the increases in intake were greater in diabetics than controls. There was no significant interaction between treatment day and diabetes.

DSLET: There were significant main effects of diabetes and DSLET at the 2, 4 and 6 hour measurements ( $p<.05)$. Generally, DSLET was more effective at increasing intake in control rats than in diabetics. This is supported by a significant diabetic $X$ DSLET interaction at 2 and 6 hours (this interaction approached significance at 4 hours, $p=.086$ ). On Day 1 , the $10 \mathrm{nmol}$ dose stimulated 2 hour intake in controls (Figure 2); the increase was not significant at 4 or 6 hours. In diabetic animals, no significant increases above baseline intake were observed at any measurement. However, an unusually high baseline and large variability in the diabetic group makes it difficult to draw conclusions about feeding responses to DSLET.

The overall Day effect (Day 1 vs. Day 4 ) was not significant at any measurement, although it approached the significance criterion at 6 hours $(p=.055)$. The interaction of DSLET and treatment day was significant at 4 and 6 hours and approached significance at 2 hours $(p=.056)$. As these interactions would suggest, the feeding responses to DSLET were slightly greater after repeated injections, at least in controls. The effect of the $10 \mathrm{nmol}$ dose was more prolonged on Day 4 , where intake was increased at 2, 4 and 6 hours. On Day 1, the increase was not significant beyond the 2 hour measurement. While none of the doses increased intake in diabetic rats on Day 1 , the $1 \mathrm{nmol}$ dose did significantly increase 6 hour intake on Day 4 (not shown). That this dose (but not the higher ones) would be effective was unexpected. However, as the 2 hour results in Figure 2 illustrate, the diabetic rats in this experiment were characterized by a large variability in feeding responses.

U50.488H: A three-factor ANOVA indicated significant main effects of $\mathrm{U} 50,488 \mathrm{H}$ at 2 and 4 hours; this effect approached significance at 6 hours $(p=.084)$. The main effect of treatment day was significant at 2, 4 and 6 hours, whereas the diabetic main effect was significant only at 6 hours (all p's <.05). The interaction between treatment day and diabetes was significant at 6 hours and approached significance at 4 hours $(p=.053)$.

No large differences in responses to $U 50,488 \mathrm{H}$ were observed between diabetics and controls (Figure 3 ). This is supported by the lack of significant interactions between diabetes and $U 50,488 \mathrm{H}$ at 2 and 4 hours (this interaction approached significance at 6 hours, $p=.071)$. On Day 1 , the highest dose tested (215 nmol) caused a significant increase in the intake of controls at 2, 4 and 6 hours. In diabetics, this dose increased 2 and 4 hour intake; these increases were smaller than those observed in non-diabetic rats given this dose. Intake of the diabetic group receiving the lowest dose tested $(21 \mathrm{nmols})$ fell just short of significance at 2 hours but was significantly increased at 4 and 6 hours.

Repeated injections did not increase the effectiveness of U50,488H. This is supported by the lack of significant interaction between $\mathrm{U} 50,488 \mathrm{H}$ and treatment day. In fact, while the intakes of the groups receiving 215 nmols were elevated on Day 4 , the difference was just short of significance for both controls and diabetics. As Figure 3 indicates, however, baseline intakes for the two groups on Day 4 were unexpectedly higher than on Day 1. 


\section{DAGO}

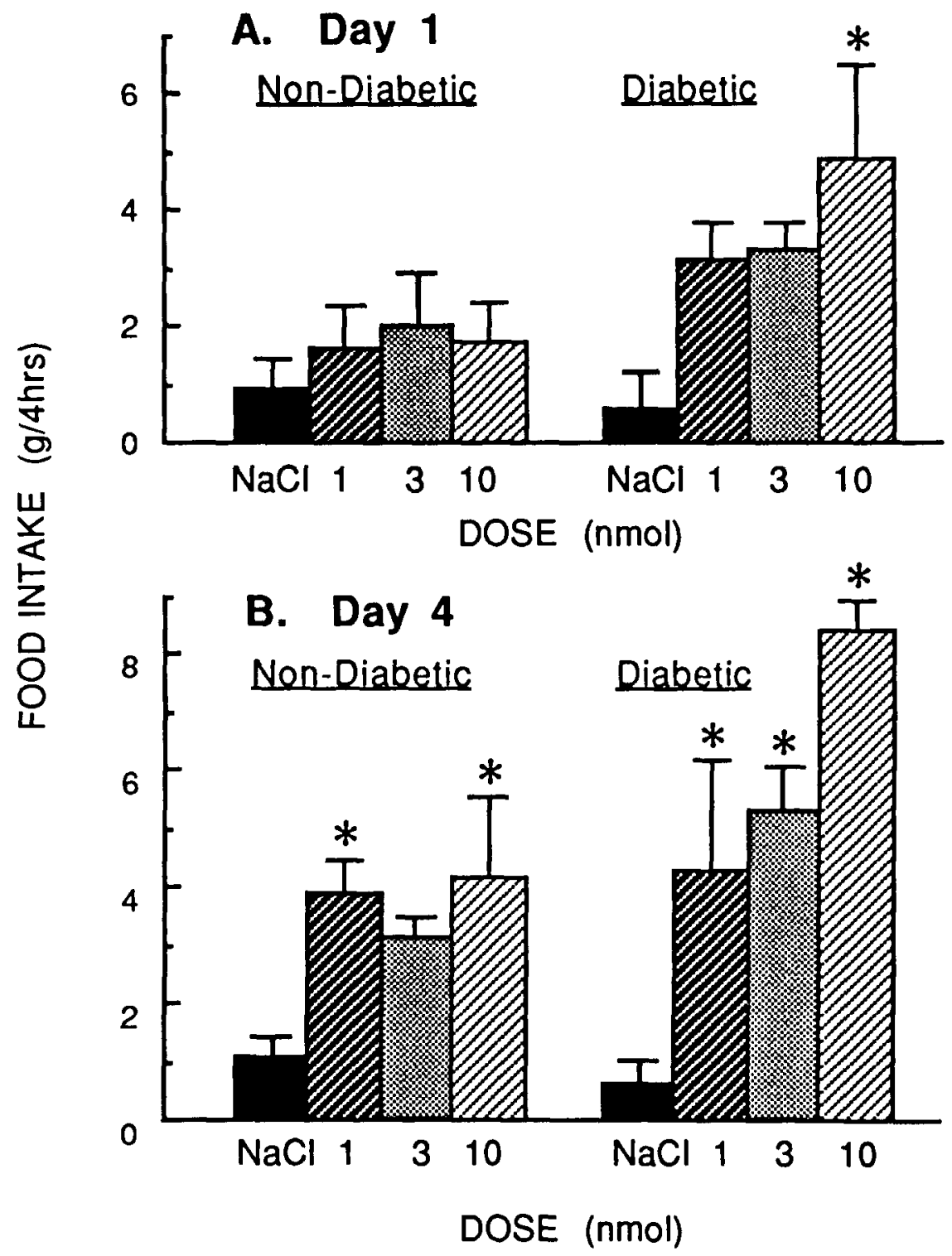

Fig. 1

A. Four hour food intake (mean \pm SEM, in grams) for non-diabetic and diabetic rats after the first icv injection of the mu agonist DAGO. B. Food intake as in (A) on the fourth day of daily icv injections of DAGO ( $n=4$ or 5 per group; ${ }^{*} p<$ .05, Dunnett's test, one-tailed). 


\section{DSLET}

A. Day 1
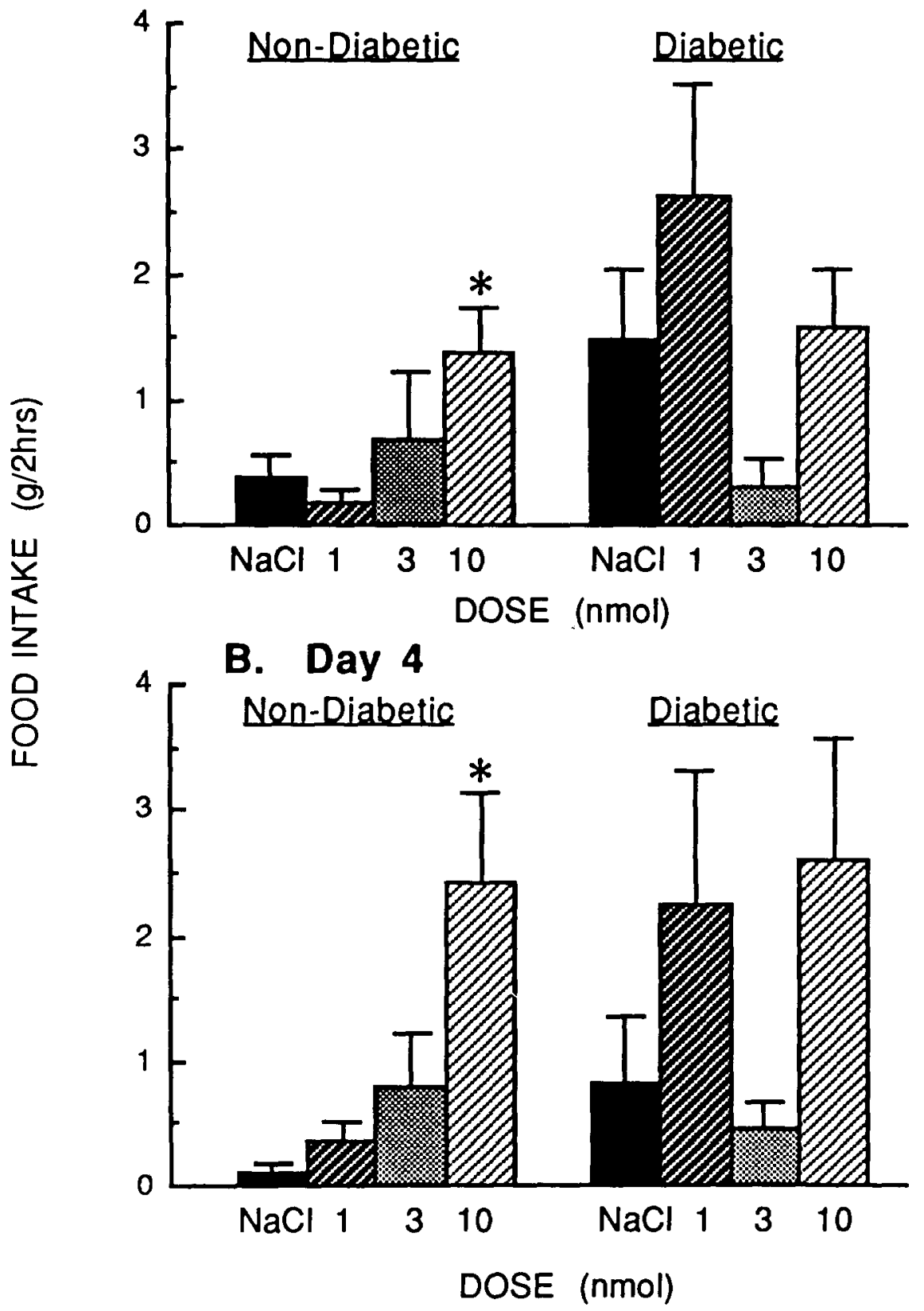

Fig. 2

A. Two hour food intake (mean \pm SEM, in grams) for non-diabetic and diabetic rats after the first icv injection of the delta agonist DSLET. B. Food intake as in (A) on the fourth day of daily icv injections of DSLET ( $n=6$ to 11 per group; ${ }^{*} p<$ .05, Dunnett's test, one-tailed). 


\section{$\underline{U}-50,488 \mathrm{H}$}

A. Day 1

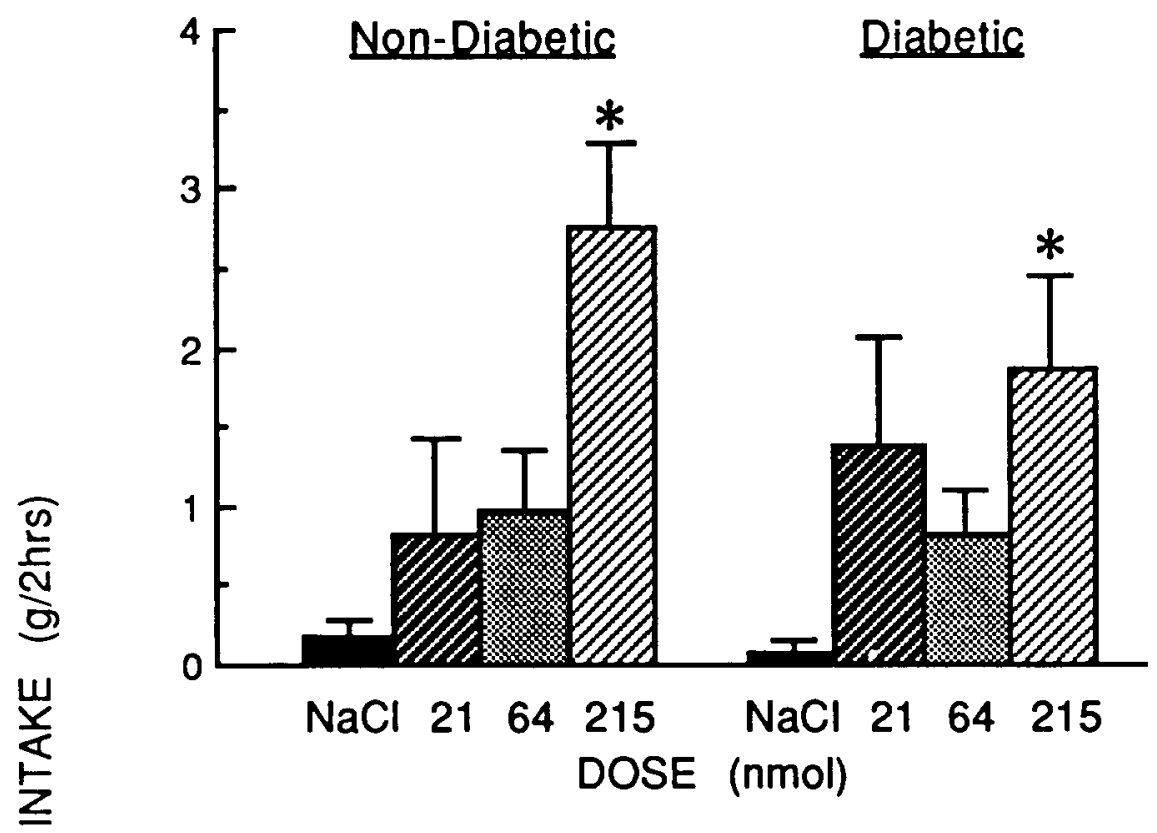

응

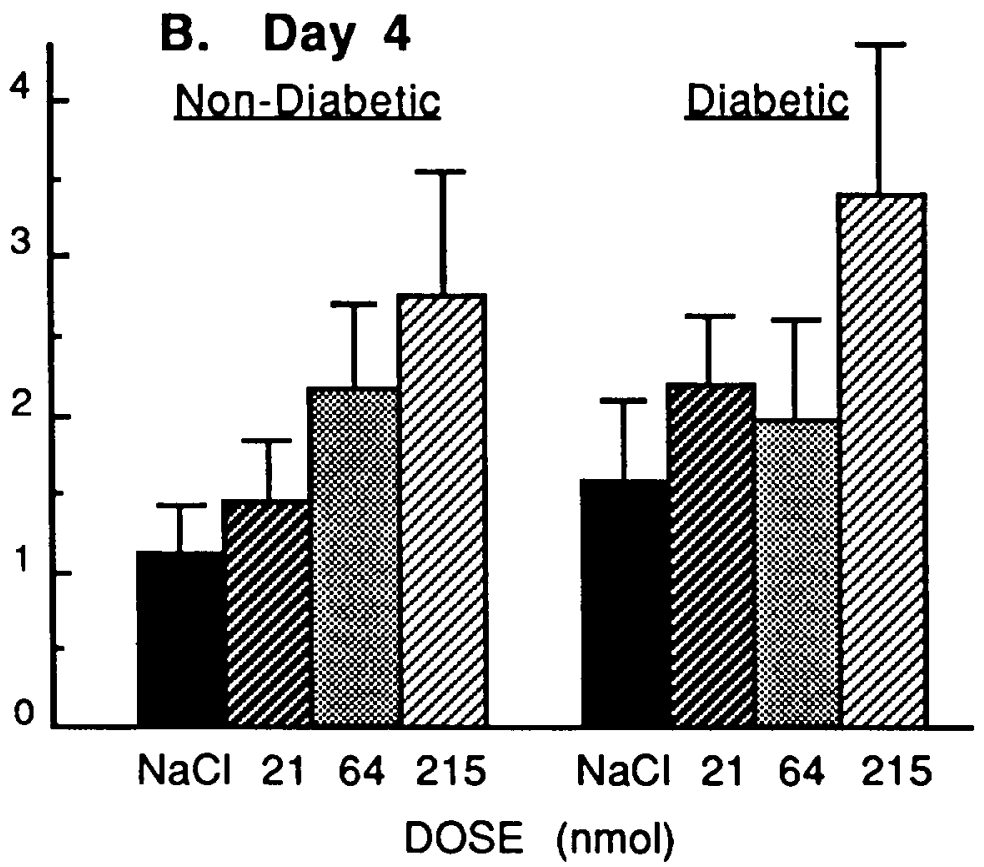

Fig. 3

A. Two hour food intake (mean \pm SEM, in grams) for non-diabetic and diabetic rats after the first icv injection of the kappa agonist $U 50,488 \mathrm{H}$. B. Food intake as in (A) on the fourth day of daily icv injections of U50,488H ( $n=6$ to 10 per group; ${ }^{*} p<.05$, Dunnett's test, one-tailed). 


\section{Discussion}

These experiments were performed to determine whether streptozotocininduced diabetes altered the feeding response to centrally administered opioid agonists. As discussed in the Introduction, some responses to opiates are altered in diabetic animals, and the changes are thought to be due to hyperglycemia. The recent report by Brase et al. (8) suggests that glucose decreases opioid receptor binding affinity in the brain. The diabetic condition would provide an elevated glucose environment in the brain, as changes in serum glucose level are generally reflected in brain glucose levels (3).

Based on in vivo and in vitro results from other laboratories, one would predict an attenuation of opioid-induced feeding in diabetic rats (3-8). However, the present study does not support this prediction. The feeding response to DAGO was greater in STZ-treated diabetic rats than in controls. In contrast, the feeding response to $\mathrm{U} 50,488 \mathrm{H}$ was not markedly affected by diabetes. Because DAGO and U50,488H act primarily at different receptors, these results suggest the possibility that the various receptors (or binding to these receptors) are differentially affected by diabetes.

The effect of diabetes on feeding responses to DSLET is not clear. This may be due in part to the large variability in feeding responses and fluctuations in baseline intake. For example, the intake of the diabetic rats given the $3 \mathrm{nmol}$ dose was much lower than that of rats given a higher or lower dose. Also, the 2 hour intake of salineinjected rats $(1.5 \mathrm{~g})$ was greater than the intake of control (non-diabetic) rats which received the $10 \mathrm{nmol}$ dose $(1.4 \mathrm{~g})$, which was significantly increased above the control baseline. Comparing groups with different baselines is problematic in the study of opioid-induced feeding, since it has been shown that opioids actually decrease intake when intake is normally elevated, e.g., after food deprivation or during the nocturnal period of the light-dark cycle $(12,13,25)$.

Another complication in the interpretation of the $U 50,488 \mathrm{H}$ results is the tendency for baseline intake to increase after repeated trials. For both diabetics and controls, baselines increased from under $0.2 \mathrm{~g}$ on Day 1 to $1.1-1.6 \mathrm{~g}$ on Day 4 . This increase was not observed in the DAGO and DSLET experiments, and cannot be attributed to differences in the agonists, since the control groups in all three experiments received only saline injections. Although we have observed this effect in other studies involving repeated testing of animals $(9,20)$, the present results, along with unpublished observations, suggest that this shift in baseline is not consistent across experiments. The cause of the shift is not known, and we are not aware of any studies that have directly addressed this problem.

That the feeding responses to some opioid agonists are often not apparent until 2-4 hours after injection may be due to other opioid effects, such as sedation or catalepsy, which would interfere with feeding. In the dose range tested, DAGO produces a clear cataleptic state which precedes the feeding response and dissipates within 1-2 hours. We and others have noted that after repeated opioid injections, the feeding responses occur earlier and/or increase in magnitude (12,26-30). This effect of chronic or repeated exposure has also been noted for opiate-induced increases in temperature and locomotor activity $(31,32)$. In the present report, the response to DAGO was greater on Day 4 than on Day 1 . This also occurred with DSLET, at least in non-diabetic rats. In relation to feeding, this effect has been explained as being due to the development of tolerance to certain effects of opioids that interfere with feeding 
behavior, thereby "unmasking" the feeding response such that it is greater and appears earlier $(2,12,26)$.

It is possible that the enhanced response to DAGO observed in diabetics is simply a consequence of decreased opioid effects on other systems which might interfere with feeding. The present experiments cannot directly address this possibility, since other behavioral effects of the agonists were not measured. However, this interpretation would be in partial agreement with other reports of decreased sensitivity to opioid agonists in diabetic animals. It leaves unexplained, however, why the actual feeding response is not also attenuated in diabetics.

\section{Acknowledgements}

This research was supported by the National Institute on Drug Abuse (DA 03999), the National Institutes of Health (NS 23565) and the Veterans Administration.

\section{References}

1. A.S. LEVINE, J.E. MORLEY, B.A. GOSNELL, C.J. BILLINGTON and T.J. BARTNESS, Brain Res. Bull 14 663-672 (1985).

2. D.J. SANGER, In: Theory in Psychopharmacology Vol 2. (S.J. Cooper, Ed.), pp. 75-113, Academic Press, London (1983).

3. G.S. SIMON, and W.L. DEWEY, J. Pharmacol. Exp. Ther. 218 318-323 (1981).

4. G.S. SIMON, J. BORZELLECA and W.L. DEWEY, J. Pharmacol. Exp. Ther. 218 324-329 (1981).

5. J.E. SHOOK, and W.L. DEWEY, J. Pharmacol. Exp. Ther. 237 841-847 (1986).

6. J.W. SIMPKINS, W.J. MILLARD, and M.J. KATOVICH, Fed. Proc. ??? A1197 (1988).

7. J.E. SHOOK, J.F. KACHUR, D.A. BRASE and W.L. DEWEY, J. Pharmacol. Exp. Ther. 237 848-852 (1986).

8. D.A. BRASE, Y.-H. HAN, and W.L. DEWEY, Diabetes 36 1173-1177 (1987).

9. A.S. LEVINE, M. GRACE, C.J. BILLINGTON, B.A. GOSNELL, D.D. KRAHN, D.M. BROWN, and J.E. MORLEY, Pharmacol. Biochem. Behav. 29 495-500 (1988).

10. D.J. SANGER, and P.S. McCARTHY, Psychopharmacol. 74 217-220 (1981).

11. R. KUMAR, E. MITCHELL, and I.P. STOLERMAN, Br. J. Pharmacol. $42473-484$ (1971).

12. J.E. MORLEY, A.S. LEVINE, M. GRACE, and J. KNEIP, Life Sci. 31 2617-2626 (1982).

13. D.J. SANGER, and P.S. McCARTHY, Psychopharmacol. 72 103-106 (1980).

14. W.R. MARTIN, A. WIKLER, C.G. EADES, and F.T. PESCOR, Psychopharmacologia 4 247-260 (1963).

15. J.W. SLOAN, J.W. BROOKS, A.J. EISENMAN, and W.R. MARTIN, Psychopharmacologia 4261-270 (1963).

16. A.S. LEVINE, J.E. MORLEY, J. KNEIP, M. GRACE, and D.M. BROWN, Physiol. Behav. 34 391-393 (1985).

17. A.S. LEVINE, J.E. MORLEY, D.M. BROWN, and B.S. HANDWERGER, Physiol. Behav. 28 987-989 (1982).

18. B.K. HANDA, A.C. LANE, J.A.H. LORD, B.A. MORGAN, M.J. RANCE, and C.F.C. SMITH, Eur. J. Pharmacol. 70 531-540 (1981).

19. G. GACEL, M.-C. FOURNIE-ZALUSKI, and B.P. ROQUES, FEBS Letters $118245-$ 247 (1980).

20. B.A. GOSNELL, M. GRACE, and A.S. LEVINE, Life Sci. 40 1459-1467 (1987).

21. B.A. GOSNELL, A.S. LEVINE, and J.E. MORLEY, Life Sci. 38 1081-1088 (1986).

22. P.F. VONVOIGHTLANDER, R.A. LAHTI, and J.H. LUDENS, J. Pharmacol. Exp. Ther. $2247-12$ (1983). 
23. J.E. MORLEY, and A.S. LEVINE, Peptides 4 797-800 (1983).

24. S.J. COOPER, W.R. MOORES, A. JACKSON, and D.J. BARBER, Neuropharmacol. 24 877-883 (1985).

25. M. KUNIHARA, M. KANBAYASHI, and T. OHSHIMA, Jpn. J. Pharmacol. 333 829835 (1983).

26. M. HEFT, G. DANIELS, A. BULLER, and A. RILEY, Soc. Neurosci. Abstr. $\geq 854$ (1981).

27. J.A. THORNHILL, M. HIRST, and C.W. GOWDEY, Pharmacol. Biochem. Behav. $\underline{4}$ 129-135 (1976).

28. J.A. THORNHILL, M. HIRST, and C.W. GOWDEY, Can. J. Physiol. Pharmacol. 57 1028-1032 (1979).

29. J.A. THORNHILL and W.S. SAUNDERS, Prog. Neuro-Psychopharmacol. Biol. Psychiat. 7 477-485 (1983).

30. B.A. GOSNELL, A.S. LEVINE and J.E. MORLEY, Pharmacol. Biochem. Behav. 19, 737-742 (1983).

31. M. BABBINI, and W.M. DAVIS, Eur. J. Pharmacol. 46 213-224 (1972).

32. J.A. THORNHILL, M. HIRST, and C.W. GOWDEY, Can. J. Physiol. Pharmacol. $\underline{56}$ 483-489 (1978). 